\title{
In memory of professor Oleg K. Tikhomirov
}

\author{
Yulia Solovieva, Luis Quintanar Rojas \\ Autonomous University of Puebla, Mexico
}

\begin{abstract}
The article "In memory of professor Oleg K. Tikhomirov" offers the personal memories of the authors and the testimony of the students and psychologists from Mexico who had the opportunity of witnessing the presence of Russian psychologist Prof. O.K. Tikhomirov at Puebla Autonomous University in 1994-1995. The article describes the circumstances of arrival and professional work of O.K. Tikhomirov as a lecturer within Mater Program in Neuropsychological Diagnosis and Rehabilitation at Psychology Faculty of Puebla University. The work of Prof. O.K. Tikhomirov in Puebla had positive consequences in academic preparation of students and specialists in psychology and neuropsychology and in fulfillment of theoretical and methodological research in following years. The authors of the article express their gratitude for the opportunity of collaboration with O.K. Tikhomirov and with Psychology faculty of Moscow State University in general. The conclusions reflect the evidence of positive effects of academic contacts and mutual experience on preparation and education of young generation of psychologists in Mexico, particularly within historical and cultural psychology and activity theory.
\end{abstract}

Key words: Russian psychology, academic experience, contacts between universities, historical and cultural psychology, activity theory.

We recall the personality and scientific achievements of Professor Oleg Konstantinovich Tikhomirov, who lectured for six months in Mexico. During this period he developed a theoretical basis for psychology at the Autonomous University of Puebla (UAP). In his academic work at UAP, he established historical-cultural foundations for psychology's activity theories (ATs), which since his demise have been distributed throughout Mexico and Latin America. Beyond his effect on the cultural traditions of psychology, Prof. Tikhomirov has had an abiding impact on the ways of thinking and has created an 'image for the world' (to use an expression coined by A.N. Leontiev).

We should begin by explaining how Tikhomirov could in such a short timespan implement his work at Puebla. This explanation might help the reader grasp the depth of our respect for Oleg Konstantinovich. However, prior to that step, we should study the professor's relationship with the article's authors, Luis Quintanar Rojas and his wife Yulia Solovieva. Luis Quintanar, a participant in the Master De- 
gree program in Psychobiology at the Faculty of Psychology, National Autonomous University of Mexico, sought to continue his higher education by studying A.R. Luria's concepts of neuropsychology.

Consequently, he applied to the Soviet Union in 1988 and was granted a scholarship to Moscow State University (MSU). During Quintanar's four years in the Soviet capital, Prof. Tsvetkova supervised his Ph.D. dissertation. After defending his doctoral tract, Quintanar returned to Mexico in 1992. There he secured employment at UAP and also established a Master's Program (MP) in Neuropsychological Diagnosis and Rehabilitation. Launched in August, 1994, the MP initially had only one teacher and researcher: Luis Quintanar himself. At that stage, the program had yet to employ other teachers or representatives of historical-cultural psychology (HCP) or of neuropsychology. As a result, it was forced to invite teachers from other Mexican universities or from abroad. Several local researchers were asked to collaborate in the MP's lecturing, but none was well acquainted with HCP or with neuropsychology. Quintanar had always planned for the program to embrace graduate students of psychology seeking an HCP orientation in general, and Luria's approach in particular. But the only way to attain this objective was to seek financial aid from Mexico's National Counsel of Science and Technology (CONACYT). Such assistance would also attract professors from MSU to lecture on neuropsychological and psychological concepts.

The neuropsychological-oriented program started receiving CONACYT support in 1995, with the financial aid used by local students (who applied for government scholarships), and by foreign teachers and researchers. The first priority was to deal with topics such as neuropsychology, with Prof. L.S. Tsvetkova invited to Mexico. She arrived at Puebla with her husband in 1994 and stayed until 1996.

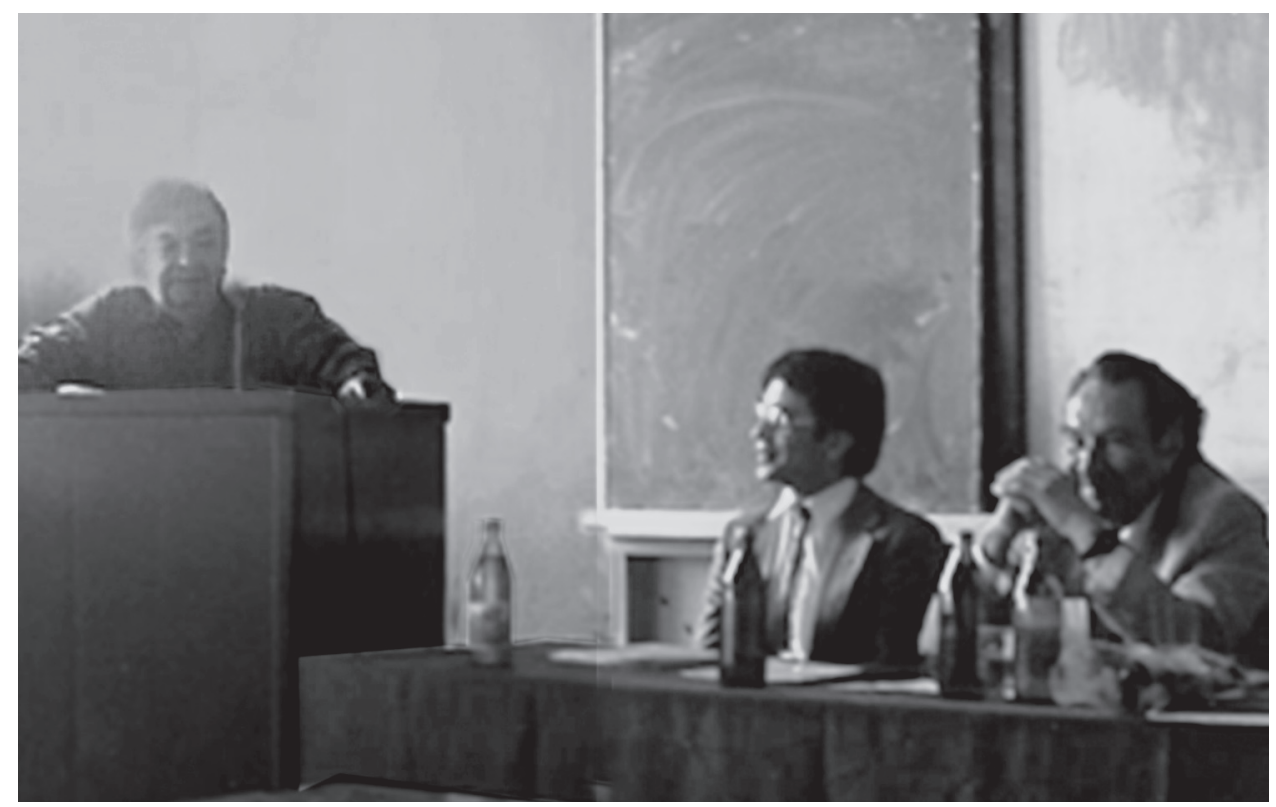

(O.K. Tikhomirov, Luis Quintanar) 
Tsvetkova was primarily invited due to the close scientific bond she had developed with Quintanar during his doctoral studies at MSU.

The latter sought her advice on subjects beyond the MP, including the invitation from MSU of specialists in general and developmental psychology. So it happened that Prof. Tsvetkova advised Quintanar to invite Prof. O.K. Tikhomirov to lecture in general psychology, and Prof. V.Ya Liaudis to teach both pedagogical and developmental topics. Oleg Konstantinovich had served as the 'methodological supervisor' for Quintanar's Ph.D. dissertation at MSU.

The following two photographs show Quintanar defending his Ph.D. dissertation at MSU on June 5, 1992.

It is important to relate that CONACYT's financial support was secured for air tickets and salary alone. In the case of L.S. Tsvetkova, it authorized a two-year salary, while for Tikhomirov, it only authorized a six-month salary (such types of financial support are at present even more difficult to attain).

In spite of the reduced social benefits, Oleg Konstantinovich agreed to lecture at UAP. He remained there for the timespan running from August 1994 through February 1995. Since CONACYT did not deal with residence-related outlays, he had to dwell in a flat rented by the UAP Faculty of Psychology for Tsvetkova. However, the three-room apartment contained adequate space for her family and for Tikhomirov.

Oleg Konstantinovich, who knew little about Mexico and nothing about Puebla, provided theoretical lectures to the first-generation MP students. The generalpsychology section of his lectures covered the basic data about HCP and ATs. As far as we know, no other neuropsychology program contains a general-psychology section, particularly from a HCP and ATs perspective.

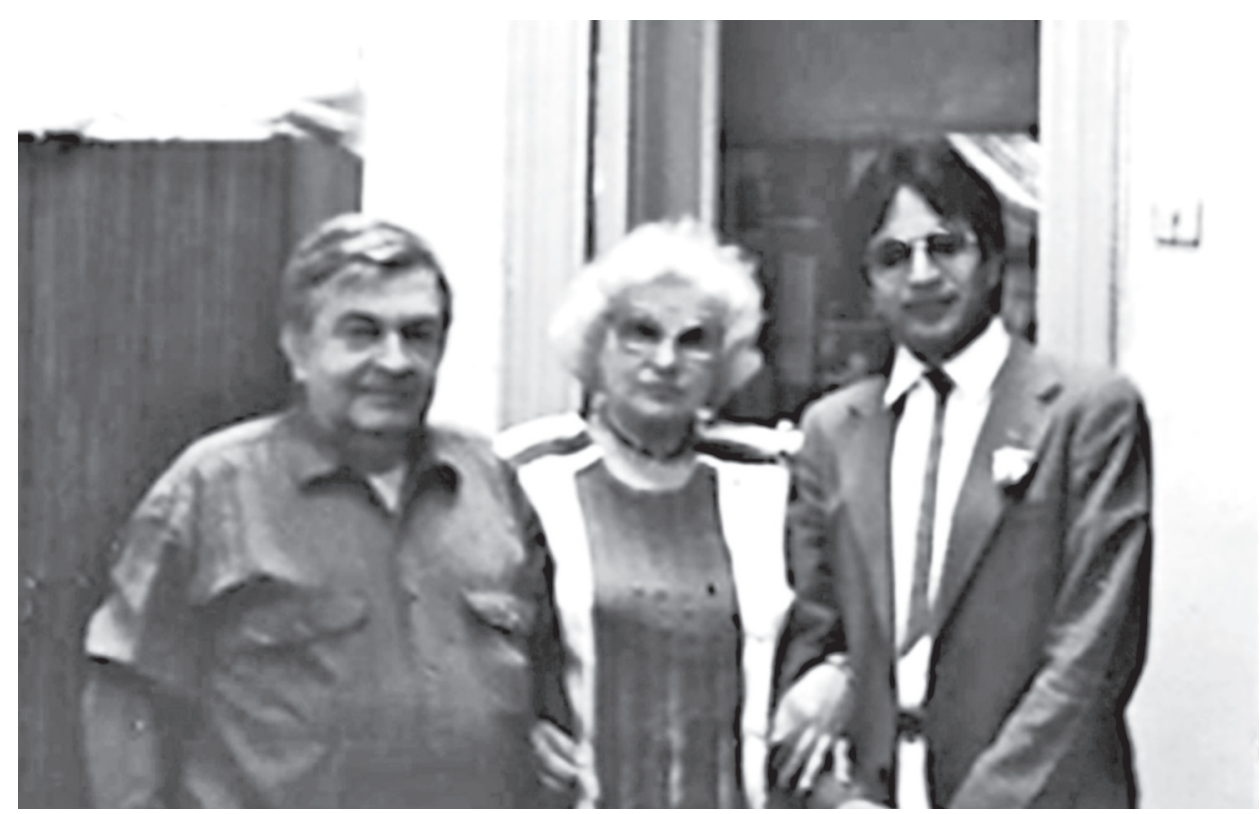

(O.K. Tikhomirov, L.S. Tsvetkova, Luis Quintanar) 
The content of Prof. Tikhomirov's lectures helped students to develop a scientific viewpoint on psychology and on its place on the frontier of natural and social sciences. Tikhomirov's lectures dealt with the history of psychology - its development in a philosophical context - and its later expansion into an independent science. His courses also covered psychological crises, starting in Vygotsky's time, and the need to identify three key factors in psychological projects: the object of study, units of analysis and methodological structure.

Students participating in the lectures could evaluate and compare major paradigms in general psychology that had previously existed separately. For instance, Oleg Konstantinovich spoke of Vygotsky's concepts on the Superior Psychological Functions, and also on the historical and cultural development of the human psyche. Subsequently, he continued his courses with the same approach, but instead focused on other historical and practical considerations. One of these was an in-depth description of the Kharkov Group. In his lectures on the contributions of Leontiev's, Galperin's and Rubinstein's psychological works, Tikhomirov covered the coincidences and differences of their variants of AT. He offered, for example, experimental and methodological approaches used by Leontiev's group, revealing its ideas about the origins and stages of psychic development. His lectures also explained other problems, such as the differences between animal and human types of reflection, and Galperin's proposal that orientation was an object of psychological study. The students in his courses were asked to evaluate the structure of psychological activity and its functional elements (including personality development, sense of activity, and image in the world). He also covered the mechanisms of new motivations, which could sometimes appear as conscious objectives of activity.

Tikhomirov's long-term objective was to present the general perspective of psychological development, while comparing the background theories of HCP with those promoted by MSU researchers (who had devoted their lives to establishing and consolidating ATs' concepts). He always focused on the bases of ATs vs. the socalled 'separations and differences' between theoretical ideas and those promoted by Vygotsky's disciples. These different views of ATs continue to influence our lives. In recalling Tikhomirov, we are reminded of the 'differences' between Vygotsky and Leontiev, Leontiev and Rubinstein (or Galperin), and the discussions about 'who was right and who was wrong', and 'who were Vygotsky's disciples'. Oleg Konstantinovich had a 'positive spirit' and maintained in his lectures historical neutrality toward ATs.

His courses contained the essence of ATs and their relationship to HCP. Regrettably, there is neither a continuation of ATs nor of their relationship with other psychological concepts. Tikhomirov stated that no existing general-psychology textbook explains the different psychological concepts or defines all of their perspectives. Lack of common sources implies lack of agreement on the terms relied on by psychologists for defining the concepts or processes being investigated. Such an outcome is not worthy of psychology, particularly when that discipline is measured according to the 'sense of morality' appearing in Tikhomirov's lectures. 
All of Oleg Konstantinovich's lectures were translated simultaneously by the authors of this article: Luis Quintanar and Yulia Solovieva. The former initiated the translation procedures, but soon thereafter Solovieva felt 'obliged' to assume his workload. Four reasons stood behind that decision: Quintanar, as the MP director, teacher and researcher, lacked free time for translation; simultaneous translation from Russian to Spanish was difficult; Solovieva - after three years in Mexico without constant work, friends or contacts - sought more regular activity; and she never obtained any reward for the translations. Her only contact, apart from family, was with Prof. L.S. Tsvetkova. After spending a year reading the available books on neuropsychology in Russian, Spanish and English, Solovieva began to assist Quintanar with Tsvetkova's lectures. By the time Prof. Tikhomirov had arrived at Puebla, Solovieva had improved her grasp of Spanish and her comprehension of neuropsychology. She did this while attending Tikhomirov's lectures alongside the Mexican MP students.

One time, Quintanar mistranslated the word 'okoshko' (diminutive for the word window) as cat ('koshka' is cat in Russian). This misinterpretation caused everyone to be confused and then to laugh. Perhaps, as a result of this mistake, Solovieva was asked to help in the translations. From that time on, until the end of Tikhomirov's tenure at UAP, she translated all of his courses. As a pre-step to doing so, she reviewed all the available material on general psychology. Her first motivation was to learn the correct translations of the terminology and the sense of his lectures. But several years afterwards her motives changed and she became a psychologist herself. This epitomized Oleg Konstantinovich's lectures, which had examined the constant flexibility of human motives.

It is worth noting that Solovieva translated not only the lectures but also the students' oral examinations. In so doing she tried to carry out her work as perfectly as possible. Tikhomirov, for his part, always encouraged and assisted the UAP students, suggesting that first "we make our statements and (then) we determine whether they make sense". He had a wonderful sense of humor, filling his lectures with real-life examples, colorful illustrations and optimistic comments (these also appeared on the students' papers).

At this stage, we would like to present some personal comments made by Prof. Tikhomirov's former students in the MP in Neuropsychology for the academic year of 1996. Most have graduated and been awarded a Master's Degree in Neuropsychology from UAP. They are now working, inter alia, as psychologists, university teachers and clinical neuropsychologists. The first generation of the MP contained 16 students at the start, of whom only 11 completed the two-year program (some failed to defend their dissertations). Listed below are some of the comments.

Humberto Tellez (Masters in Neuropsychology from UAP; lecturer at UAP; presently, serving as a teacher in the Autonomous University of Nuevo León, Monterrey). A student of Prof. Tikhomirov, Tellez was among the 'first generation' to participate in the MP.

"The opportunity to listen to Dr. Tikhomirov's discourses was an incomparable experience for the first-generation students of the Master's Program in Neuropsychological Diagnosis and Rehabilitation (offered by the) Autonomous University in Puebla's 
Faculty of Psychology. The lectures ... were simultaneously translated by Yulia Solovieva and Luis Quintanar. All classes were rather long, with each session dedicated to a specific theme.

The thematic scheme developed in each exposition by Prof. Tikhomirov was perfectly organized and included a precise line of scientific reasoning. Such a line gave us an opportunity to penetrate into the study of psychological processes (and create) a useful format for constant analyses. Each class could be considered a perfect scientific lecture.

We ... interacted with one of the greatest psychologists that has lived and who (helped) construct the history of the Soviet Union in psychological science. His relations with us were warm and he always exhibited a wonderful (sense of) humor.

His classes ... were presented in the form of oral dissertations (having) great profundity. (They) promoted responses from us all; ... the form and structure of his ideas (were) always conducive to reasoning. Dr. Tikhomirov rarely moved from one place to another during his lectures. He came into the classroom, placed his chair in a comfortable position, and put his notes in front of him alongside his watch.

I remember only one occasion in which he stood up and drew a scheme on the blackboard. He did not (use) images, diagrams, pictures, photographs or slide projections. His theoretic domain was obvious for everyone (present); it was very refined.

He facilitated theoretical analyses of psychological processes from the perspective of the Soviet school of psychology, (using) references to various Soviet psychologists.

Neuropsychology needs a general psychological concept as a base, and Professor Tikhomirov has presented ... the richness of Soviet psychology. The theoretical domain enables us to apply different concepts in clinical practice.

We were lucky ... to have been his students.

I would like to thank Dr. Quintanar for inviting Dr. Tikhomirov and for coordinating this Master's Program."

Maria Elena Navarro (Master in Neuropsychology from UAP; Ph.D. in Psychology; at present, working as a professor at the Autonomous University in San Luis Potosi). She was among the Mexican teachers who took part in the first- and second-generation of the MP, which took place while Tikhomirov had tenure at UAP. In his lectures, given at Puebla University Hospital, Oleg Konstantinovich dealt with general psychology and HCP. Quintanar and other Mexican researchers participated in these courses.

"As a human being he was accessible, dedicated to his academic work and prudent in all his expressions. His lectures helped me (grasp) the object of study in social psychology and the process of learning. His courses were important and the basis for my academic preparations. (They enabled me) to obtain knowledge from (a wise person) 'first hand'.

I consider that his presence for students and teachers (alike) was a rich experience ... that could not be repeated or reproduced. I am grateful for this opportunity." 
Vicente Arturo López Cortés (Masters in Neuropsychology from UAP; teacher and researcher at the same institution; at present, a Ph.D. student in Neuropsychology at the University of Salamanca, Spain). Quintanar invited him as well as other psychology undergraduates and MP graduate students at UAP to listen to some lectures given by Prof. Tikhomirov in 1995.

"While Dr. Tikhomirov was visiting Puebla, I was an undergraduate in the Psychology Faculty of the Autonomous University in Puebla. I ... helped Dr. Tikhomirov in two lectures because I was invited by Dr. Quintanar. I am grateful to Dr. Quintanar as he was the (primary figure) responsible for my personal, human and professional development.

I would like to divide my opinion (of Tikhomirov) into two parts. The first is related to the serious Teacher who transmitted ... formal knowledge in a clear and accessible manner. His expositions helped me (understand) the emotional regulations of activity and of thinking, which determine the major part of human behavior. Such explanations enabled me to change my previous ... holistic and biological (concepts) and comprehend the human psyche. Such understanding still predominates (in) psychology. Unfortunately, my scientific concepts and thought structures were far from his level. I was not prepared (at that stage) to understand more profoundly the dimensions of his words.

The second part is related to the Teacher who (encouraged) direct communication with his pupils, always (showing) that gladness, goodwill and sympathetic coexistence are not distinct from mutual respect. (Regrettably), my lack of knowledge and shyness did not permit me to establish a broader contact with Dr. Tikhomirov. I also remember how Dr. Quintanar presented me and other classmates who were ... taking part in the Master's Program in Neuropsychology to Dr. Tikhomirov. This was very important for us. (Though) there was a vast difference between us and the first generation of Master's students, we never felt the distinction from him. He shared his smile and his friendliness all the time. I believe it is possible to motivate others to think, and one of my motives is to defend what I respect. In this case, Dr. Tikhomirov and other teachers ... helped me to select a professional life. I say 'thank you' (wherever) you are."

Yulia Solovieva (Masters in History Sciences; Ph.D. in Psychology from MSU; from 1998, a teacher and researcher in the MP in Neuropsychology on the Faculty of Psychology at UAP). During Tikhomirov's six-month tenure at Puebla, she was a 'free assistant' for the MP lectures and started translating them on a voluntary basis from Russian into Spanish. The translations lasted for two years.

"My work experience alongside Oleg Konstantinovich Tikhomirov for six months in 1995 ... was specifically of an academic (nature). I guess I was too inexperienced then ... to assimilate all the richness of his personality. My aspiration was to implement the proper translation of lectures in general psychology, and ... I became extremely interested in all themes that I heard from him. What I remember now is that I was reading and (re-reading) all the books that I could (get hold of), starting with Vygotsky and ending with Tsvetkova and Tikhomirov themselves. I never ... had a conscious interest in studying psychology nor in preparing for examinations. 
I have to admit that at that moment I did not wish to study psychology... I made such a decision later on, (after) I met Prof. N.F. Talizina [who supervised her dissertation].

I remember Oleg Konstantinovich as quiet and pacific ... a dedicated lecturer, extremely patient with students and colleagues. He always showed profound respect and friendship to us, his colleagues and pupils, and to me, his interpreter. He was interested in Mexican culture and traditions, and our way of life.

I could not tell if it was or was not his real purpose, but he achieved an influence indirectly on many people (including me). His influence enabled me to (recognize) the need for constant study of general psychology and revision of its concepts and terms. I know that without his lectures and collaboration ... I could not have passed the exams and defended my Ph.D. dissertation at the faculty of Psychology in Moscow State University. I am really grateful to him. It is a shame... I never had a chance to meet him again and express my gratitude."

During his tenure at UAP, as Solovieva stated, Tikhomirov expressed interest in Mexico's history, folk art, traditions and way of life. He always was on the lookout for general literature about Mexico. Unfortunately, most of the material at that time was written in Spanish rather than in Russian or English. But in one instance he was given a book entitled 'The Legend of Quetzalcoatl', which Quintanar had brought back upon completion of his studies at MSU.

On various occasions Tikhomirov spent his free time with students. In the picture below he is sitting with several students and Boris Lvovich Kagan, Prof. L.S. Tsvetkova's husband, celebrating her birthday.

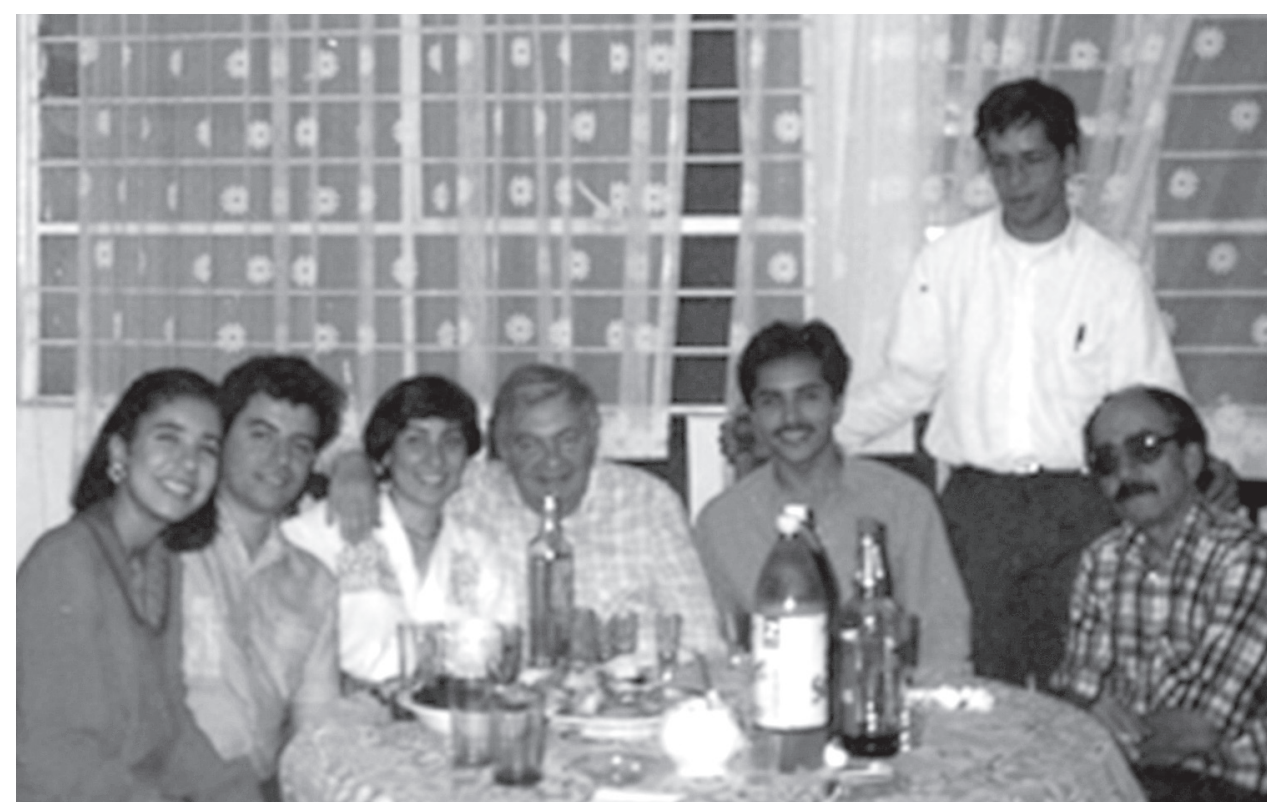

(from left to right: Ana Ruth Díaz, Víctor Patiño, Rocío Ibarrondo, O.K. Tikhomirov, Humberto Téllez, Angel Ontiveros and B.L. Kagan) 
Neuropsychology is mostly separate from the other psychological fields. Consequently, it does not share ATs' definitions with them, and, when it does, they tend to be modified AT versions. Such a situation, at MSU as well as at universities in other countries, now exists for both developmental and clinical neuropsychology. One potential means of coping with this 'academic shortfall' would be to create contacts between general psychology and neuropsychology (in particular between the ATs in general-psychology and in Luria's concept of neuropsychology). Our approach is derived from knowledge and theoretical reflections garnered from Tikhomirov's lectures. With respect to the MP at UAP, we feel it was enriched by his lectures. In his honor, we have not yet included in the program a course entitled 'general psychology'. Nonetheless, seminars on neuropsychological theory, assessment, and adult and childhood rehabilitation do contain fundamental aspects of general psychology from both historical-cultural and ATs perspectives. Moreover, the preparation of our Mexican and foreign students reflects MP's methodological, theoretical and practical strengths.

Normally, scientific contributions can be measured by the number of articles appearing in prestigious journals or by their indexes of citations. But the real contribution is a function of the personalities involved. The concepts followed by Tikhomirov's disciples would reflect such a contribution. Though he did not plan so during his tenure in Mexico, he has affected the disposition of neuropsychology and developmental psychology in our country and in all of Latin America.

Oleg Konstantinovich gave as much as he could, though not always in a conscious manner. Regrettably, we could not always respond appropriately, nor could we express the depth of our gratitude. However, we are certain that his work and personality were key factors in the development of psychology as a human science. 